\title{
Managing Cachexia and Improving Quality of Life in Cancer Patients Using Novel Nutritional Supplements: A PAN India Study
}

\section{Snany Surendran', Radha Devi², Raktim Chattopadhyay ${ }^{3}$, Anubhab Mukherjee $^{3 *}$, Shrikant Charde ${ }^{3 *}$}

${ }^{1}$ MVR Hospital, Calicut, India

${ }^{2}$ Indo American Hospital, Hyderabad, India

${ }^{3}$ Esperer Onco Nutrition Pvt Ltd, Mumbai, India

Email: ^dranubhab@esperernutrition.com, ${ }^{\star}$ drshrikant@esperernutrition.com

How to cite this paper: Surendran, S., Devi, R., Chattopadhyay, R., Mukherjee, A. and Charde, S. (2022) Managing Cachexia and Improving Quality of Life in Cancer Patients Using Novel Nutritional Supplements: A PAN India Study. Journal of Cancer Therapy, 13, 88-104.

https://doi.org/10.4236/jct.2022.132007

Received: January 15, 2022

Accepted: February 19, 2022

Published: February 22, 2022

Copyright $\odot 2022$ by author(s) and Scientific Research Publishing Inc. This work is licensed under the Creative Commons Attribution International License (CC BY 4.0).

http://creativecommons.org/licenses/by/4.0/

(c) (i) Open Access

\begin{abstract}
Cancer patients develop cachexia due to systemic inflammation, negative protein and energy balance. Esperer Onco Nutrition (EON) has come up with innovative nutritional supplements (EON Therapy) that help patients take the rigours of cancer therapy thereby improving prognosis and Quality of Life (QoL). This Post-marketing surveillance study was undertaken on 38 volunteers to assess the impact of EON therapy on cachexia and QoL of patients undergoing curative treatment. Body weight and biochemical parameters of the volunteers were recorded at each visit. Volunteers were assessed using ECOG Scale and Malnutrition Screening Tool (MST) to assess impact of nutritional supplements on QoL. Weight loss was observed in most of the patients for first two visits but the patients gained weight over subsequent visits and average weight at end of the study was higher than initial weight. At the end of study 22 of 38 volunteers gained weight and 7 volunteers maintained initial weight. The biochemical parameters either showed improvement or remained same. The QoL analysis indicated a marked improvement in physical wellness and nutritional status and no adverse effects were reported. In conclusion, the study underlines importance of research based on nutritional supplements for cancer patients for better disease management and prognosis.
\end{abstract}

\section{Keywords}

Cancer, Cachexia, Nutritional Intervention, Quality of Life 


\section{Introduction}

Ever since the time of Hippocrates, cancer cachexia, with gross loss of skeletal muscle and adipose tissue, remains a clinical impasse often occurring in presence of malnutrition [1] [2]. Malnutrition is a persistent complication in cancer patients, whose ubiquity and degree largely pivot on tumour stage and site of occurrence [3]. Bleak ramifications of the malady are extended hospitalization, impaired response to cancer treatment, a higher degree of systemic treatmentrelated toxicity, compromised competency of immune system, reduced level of activity, vitiated Quality of Life (QoL) with an unpleasant prognosis rendering unremitting emotional, social and financial burden on the families of afflicted people [4] [5]. Nonetheless, nominal weight loss during chemo/radiotherapy (CRT) has a consequence of significantly reduced overall survival [6]. There is no denying the fact that comprehensive and adequate personalized care of this disorder demands substantial knowledge of the possible causes and currently available arsenals for treatment [7]. Of a myriad of contributing factors, altered metabolic activity in patients with advanced cancer, often indicated by a systemic inflammatory response syndrome, is known to propel catabolism which redisseminates body resources leading to enhanced morbidity and mortality [8].

Since the cure for many cancers remains a daunting obstacle, it is imperative to adopt supportive care for alleviating the plight of long-term cancer treatment with a moderate rate of success [9]. Nutritional support is a gradual intervention, which should be meticulously managed and patient oriented after assessing the clinical status, nutritional condition, clinical status, and planned treatment. The objective of this modality is to prevent and/or treat malnutrition allowing effective execution of cancer therapy, ameliorate prognosis, safeguard function of organs and preserve the QoL [10] [11]. It can unarguably be stated that perspective and inclination towards addressing the issue vary noticeably among institutions and oncologists across the globe albeit direction and guidance for governing nutritional support for malignancy have been provided [12] [13]. The discrepancy could be attributed to a limited number of clinical trials aimed at deciphering the role of nutritional support in cancer, dearth of structured collaboration between clinical oncologists and nutrition specialist and inadequate awareness of nutritional issues among health care professionals [14]. Caution should also be exercised to recognize the growing market of "alternative anticancer diets" which are not supported by clinical evidence.

To this end, Esperer Onco Nutrition has come up with EON Therapy to combat cancer cachexia providing a palpable solution to the malnutrition during the prognosis. Importantly, a phase IV post marketing surveillance study was performed in India to evaluate safety and efficacy of the same. We now have evidence (based on measuring weight and other biochemical parameters) to exhibit that EON Therapy, administered as and when recommended, is helpful in terms of cachexia and improving QoL in cancer patients. We envisage that this clinical outcome will pave the way for many future studies with nutritional supplemen- 
tation in patients undergoing various treatment modalities of cancer.

\section{Materials and Methods}

\subsection{Study Design and Objectives}

This study was a prospective, open label, multi centric post marketing surveillance (PMS) to evaluate safety and efficacy of novel oral nutritional supplements (EON therapy) developed by Esperer Onco Nutrition. The study was designed to assess if usage of EON therapy help managing body weight, key biochemical parameter and QoL of cancer patients. Ethical approval was obtained from Institutional Ethics Committee of each of the hospital wherein patients were enrolled for the PMS study. After obtaining informed consent, screening procedures were performed to assess eligibility of the patients based upon predefined inclusion exclusion criteria. In short, eligible patients were male and females residing in India, above 13 years of age, who gave written informed consent and were cytologically or histologically confirmed cases of malignant neoplasm who were receiving or planned to receive any cancer therapy (Chemotherapy, Radiotherapy or a combination or surgery and chemotherapy) with a progressive weight loss. Patients on parenteral nutritional support or with clinically significant uncontrolled cardiovascular, renal or pulmonary diseases were considered ineligible. Pregnant or lactating females were also considered ineligible.

The patients were explained about importance of being in touch with study staff on regular basis and maintenance of dosing diary. After a run-in period of two to three days, patients were put on EON therapy.

\subsection{Oral Nutritional Supplementation and Assessments}

Patients were administered with EON therapy (Es Invigour and Es Fortitude Protect) orally as an enteral nutrition therapy at the dose decided by the treating physician in conjunction with the nutritionist. Both the products in powder form were reconstituted in water for immediate consumption. The recommended daily dose was two sachets of both the products in two divided doses for a minimum of three months or till the end of chemotherapy cycle. The patients were advised to be on regular diet during the period of treatment. Efficacy was assessed by recording body weight, biochemical parameters and BMI at baseline and at every visit.

Impact of nutritional intervention on QoL was indirectly assessed using ECOG Performance Status Scale along with nutritional screening using Malnutrition Screening Tool (MST) at each visit [15] [16]. ECOG Scale is a well-accepted and widely used to assess changes in patients' level of functioning in terms of their ability to care for themselves, daily activity, and physical ability. MST is an easy to use two question tool that is usually used to assess malnutrition status of an individual. Outcome of ECOG and MST scales were together used to assess impact of nutritional supplements on QoL Adverse events attributed to nutritional supplement were also recorded. 
The results were evaluated using descriptive and inferential statistical parameters. Changes in average body weight over each of the visits were compared using paired $t$ test. Paired t test was also used to compare change in each of the biochemical parameter monitored over the study duration.

\section{Results}

Informed consent was obtained from 53 patients for enrolment in the study of which 38 volunteers were recruited for the study post screening using predefined inclusion and exclusion criteria (Table 1). The recruited patients included both males (28) and females (10) with age varying between $21-60$ years. All the patients were on curative therapy with most of the patients taking one or more chemotherapeutic agents. Detailed baseline demographic data of recruited patients is presented in Table 2. Patients were administered enteral nutritional supplements (Es Invigour and Es Fortitude Protect). The composition of both the supplements is presented in Table 3 and Table 4.

\subsection{Impact of EON Therapy on Body Weight}

Change in body weight of patients was recorded post administration of EON therapy, as an enteral nutrition supplement, at the dose decided by the treating physician/nutritionist (two sachets a days for each product in two divided doses) for a minimum of three months or till the end of the chemotherapy cycles. Figure 1(a) depicts the change in body weight of individual volunteers over six chemotherapy cycles. Out of 28 volunteers, 22 volunteers (nearly 60\%) gained weight over the study period. Close to $20 \%$ of volunteers were able to maintain their initial weight with insignificant gain or loss of weight. Weight loss was observed in rest of $20 \%$ volunteers with only two volunteers losing more than $5 \%$ of initial weight with maximum weight loss being $7 \%$.

Table 1. Inclusion and exclusion criteria for volunteer recruitment.

\section{Inclusion Criteria}

Exclusion Criteria

- Cytologically or Histologically confirmed diagnosis of malignant neoplasm who are receiving or planned to receive any cancer therapy (Chemotherapy,

Radiotherapy or a combination or surgery and chemotherapy) with progressive weight loss

- On oral nutrition support or tube feeding

- Has no contraindication to Enteral Nutrition (EN)

- Willing to abstain from other nutritional/protein supplements throughout the study period

- Patients having ECOG (Eastern Cooperative Oncology Group) performance status score of 2 or less

- Life expectancy of more than 6 months

- Capable or intake/swallowing plant-based foods foreseen by the investigator

- Written informed consent according to the local Ethics Committee requirements

- Patients on or requiring Parenteral Nutrition (PN) support

- Patients with known history of food allergy

- Known HIV infection

- Pregnancy or lactation(females)

- History of alcohol abuse

- Clinically significant uncontrolled cardiovascular, renal or pulmonary diseases

- Current treatment with antipsychotics

- Ability to maintain a daily contact (by phone or email) with the study staff for the communication of crucial clinical information, including daily body weight, blood pressure, health status and adverse events during the study 
Table 2. Baseline demographic and disease characteristics.

\begin{tabular}{|c|c|}
\hline \multicolumn{2}{|c|}{ Demographic and Disease Characteristics } \\
\hline Age in years (Average, Highest, Lowest) & $49.0,60.0,21.0$ \\
\hline Males (N) & 28 \\
\hline Females $(\mathrm{N})$ & 10 \\
\hline Weight in Kg (Average, Highest, Lowest) & $71.6,102.0,31.2$ \\
\hline Type of Cancer $(\mathrm{N})$ & $\begin{array}{c}\text { Oral: } 9 \\
\text { Gastrointestinal: } 7 \\
\text { Endometrium: } 7 \\
\text { Lung: } 5 \\
\text { Breast: } 4 \\
\text { Bladder: } 3 \\
\text { Others: } 3\end{array}$ \\
\hline Patients on Chemotherapy $(\mathrm{N})$ & 30 \\
\hline Patients on Radiation Therapy (N) & 6 \\
\hline Patients on Chemotherapy + Radiation Therapy (N) & 10 \\
\hline Patients with Surgical Resection Only (N) & 2 \\
\hline $\begin{array}{c}\text { Patients with Surgical Resection prior to } \\
\text { Chemotherapy or Radiation therapy or both }(\mathrm{N})\end{array}$ & 23 \\
\hline
\end{tabular}

Table 3. Nutritional information of Es invigour.

\begin{tabular}{|c|c|c|}
\hline NUTRIENTS & UNIT & Per Serving (33 g) \\
\hline Energy & Kcal & 150.3 \\
\hline Protein & g & 11.6 \\
\hline Fat & g & 5.8 \\
\hline Saturated fatty acids & $\mathrm{g}$ & 0.7 \\
\hline Medium Chain Triglycerides & g & 4.5 \\
\hline Omega 3 Fatty Acid & $\mathrm{mg}$ & 20 \\
\hline Carbohydrate & g & 13 \\
\hline Fructo-oligosaccharides & g & 1 \\
\hline Choline & $\mathrm{mg}$ & 25 \\
\hline Inositol & $\mathrm{mg}$ & 10 \\
\hline Inulin & g & 2 \\
\hline BCAA (L-Leucine:L-Isoleucine:L-Valine: 2:1:1) & $\mathrm{mg}$ & 148.5 \\
\hline L-Glutamine & $\mathrm{mg}$ & 0.2 \\
\hline Taurine & $\mathrm{mg}$ & 20 \\
\hline L-Carnitine & $\mathrm{mg}$ & 15 \\
\hline Vitamin A & $\operatorname{mcg}$ & 297 \\
\hline$\beta$-Carotene & $\mathrm{mg}$ & 2.4 \\
\hline Vitamin D & IU & 200 \\
\hline
\end{tabular}




\section{Continued}

\begin{tabular}{|c|c|c|}
\hline Vitamin E & $\mathrm{mg}$ & 5 \\
\hline Vitamin K1 & $\operatorname{mcg}$ & 27.2 \\
\hline Vitamin B1 & $\mathrm{mg}$ & 0.6 \\
\hline Vitamin B2 & $\mathrm{mg}$ & 0.7 \\
\hline Niacin & $\mathrm{mg}$ & 8 \\
\hline Pantothenic acid & $\mathrm{mg}$ & 5 \\
\hline Vitamin B6 & $\mathrm{mg}$ & 1 \\
\hline Vitamin B8 & $\operatorname{mcg}$ & 100 \\
\hline Folic acid & $\operatorname{mcg}$ & 100 \\
\hline Vitamin B12 & $\operatorname{mcg}$ & 0.7 \\
\hline Vitamin C & $\mathrm{mg}$ & 20 \\
\hline Sodium & $\mathrm{mg}$ & 132 \\
\hline Potassium & $\mathrm{mg}$ & 154 \\
\hline Calcium & $\mathrm{mg}$ & 30 \\
\hline Phosphorus & $\mathrm{mg}$ & 30 \\
\hline Magnesium & $\mathrm{mg}$ & 34 \\
\hline Iron & $\mathrm{mg}$ & 1.7 \\
\hline Zinc & $\mathrm{mg}$ & 1.2 \\
\hline Copper & $\operatorname{mcg}$ & 0.27 \\
\hline Manganese & $\operatorname{mcg}$ & 0.5 \\
\hline Chloride & $\mathrm{mg}$ & 100 \\
\hline Iodine & $\operatorname{mcg}$ & 53 \\
\hline Chromium & $\mathrm{mcg}$ & 6.6 \\
\hline Selenium & $\operatorname{mcg}$ & 6.6 \\
\hline Molybdenum & $\operatorname{mcg}$ & 14 \\
\hline
\end{tabular}

Table 4. Nutritional information of Es fortitude protect.

\begin{tabular}{ccc}
\hline NUTRIENTS & UNIT & Per Serving (20 g) \\
\hline Energy & Kcal & 83.7 \\
Protein & $\mathrm{g}$ & 4.5 \\
Fat & $\mathrm{g}$ & 1.7 \\
Omega 3 Fatty Acid & $\mathrm{mg}$ & 10 \\
Medium chain triglycerides (MCT) & $\mathrm{g}$ & 1.4 \\
Carbohydrate & $\mathrm{g}$ & 12.6 \\
L-Glutamine & $\mathrm{mg}$ & 1000 \\
Curcumin & $\mathrm{mg}$ & 75 \\
BCAA (2:2:1) & $\mathrm{mg}$ & 250 \\
\hline
\end{tabular}




\section{Continued}

\begin{tabular}{|c|c|c|}
\hline Bioperine & $\mathrm{mg}$ & 1 \\
\hline CoQ10 & $\mathrm{mg}$ & 50 \\
\hline Vitamin A & $\mathrm{mcg}$ & 600 \\
\hline B-Carotene & $\mathrm{mg}$ & 4.8 \\
\hline Vitamin D & $\mathrm{mcg}$ & 400 \\
\hline Vitamin E & $\mathrm{mg}$ & 5 \\
\hline Vitamin K1 & $\mathrm{mcg}$ & 27.5 \\
\hline Vitamin B1 & $\mathrm{mg}$ & 0.3 \\
\hline Vitamin B2 & $\mathrm{mg}$ & 0.35 \\
\hline Niacin & $\mathrm{mg}$ & 4 \\
\hline Pantothenic Acid & $\mathrm{mg}$ & 2.5 \\
\hline Vitamin B6 & $\mathrm{mg}$ & 0.5 \\
\hline Folic acid & $\mathrm{mcg}$ & 100 \\
\hline Vitamin B12 & $\mathrm{mcg}$ & 1 \\
\hline Vitamin C & $\mathrm{mg}$ & 40 \\
\hline Biotin & $\mathrm{mcg}$ & 50 \\
\hline Selenium & $\mathrm{mcg}$ & 60 \\
\hline Zinc & $\mathrm{mg}$ & 12 \\
\hline $\begin{array}{l}\text { A (Streptococcus thermophilus, } \\
\text { n longum, Bifidobacterium breve, } \\
\text { ium infantis, L. acidophilus, L. } \\
\text { m, L.casei and L. bulgarius) }\end{array}$ & $\mathrm{cfu}$ & 2 billion \\
\hline
\end{tabular}

A statistically significant $(\mathrm{p}<0.05)$ drop in average weight was observed during first two visits of volunteers. However more importantly, the average weight of volunteers gradually increased over next four cycles and average weight at the end of study duration being significantly $(\mathrm{p}<0.05)$ higher than initial average weight and average weight after second and third cycle of chemotherapy. The initial drop in average weight during first few cycles may be attributed to detrimental effect of chemotherapy on the volunteers and indicates that volunteers take some time to respond to EON therapy. However, over a period of study duration the beneficial effect of EON therapy is distinctly visible indicating anti cachexia effect of EON therapy that help overcome negative protein and energy balance (Figure 1(b)).

\subsection{Impact of EON Therapy on Biochemical Parameters}

Several biochemical parameters were assessed for all volunteers during each visit, and the average of all the biochemical parameters before and after the treatment is presented in Table 5. Most of the biochemical parameters showed statistically and clinically significant improvement (haemoglobin, liver function, renal 
(a)

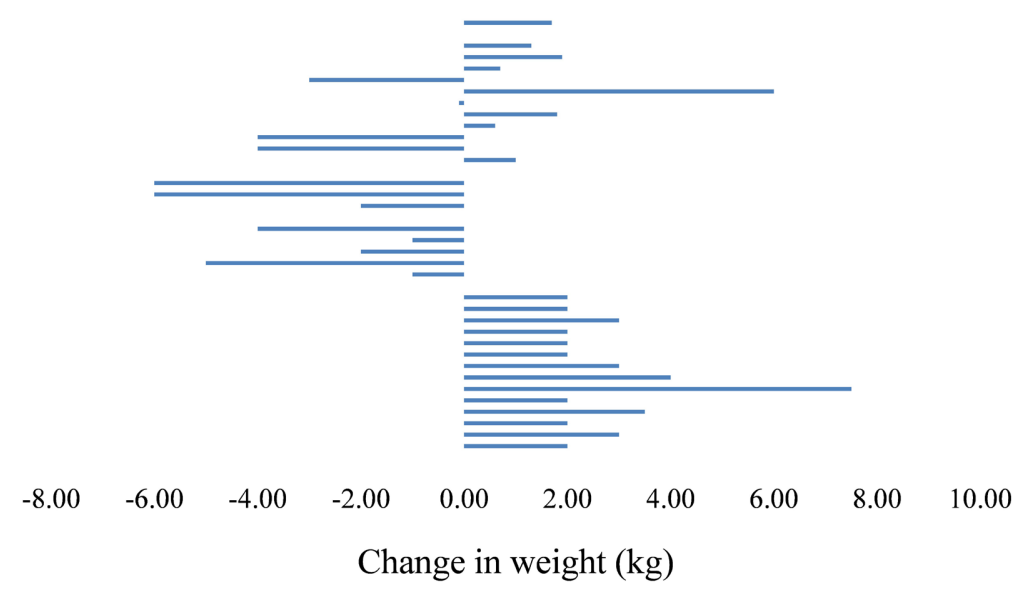

(b)

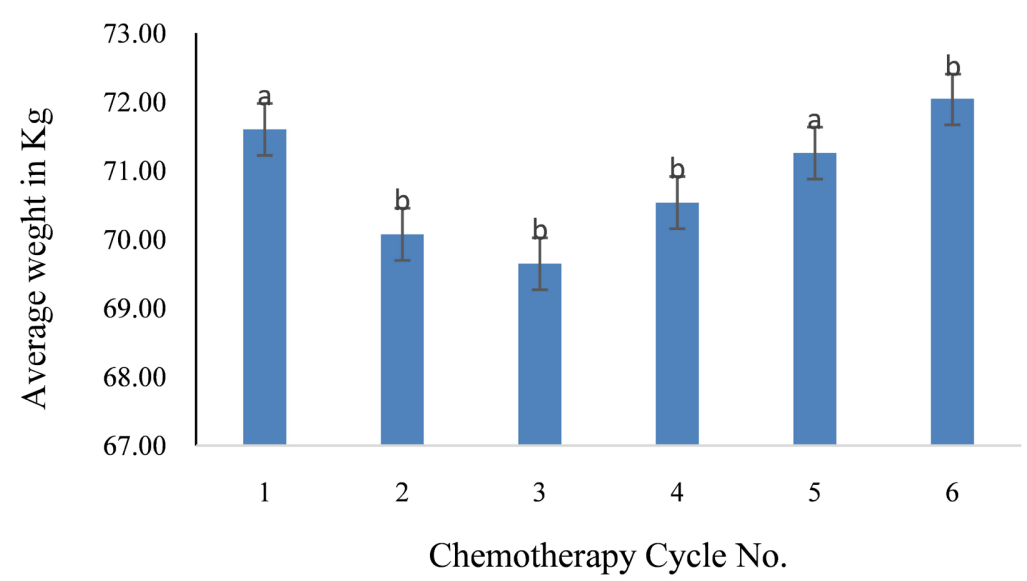

Figure 1. Weight data of volunteers (a). Change in weight of volunteers over the period of study (b). Average weight of the volunteers at the end of chemotherapeutic cycles (a and $\mathrm{b}$ are statistically different at $\alpha=0.05$ ).

Table 5. Summary of biochemical data.

\begin{tabular}{|c|c|c|c|}
\hline Test Parameter & & Mean & STDEV \\
\hline \multirow{2}{*}{ Haemoglobin $* * *$} & Before & 10.99 & 2.10 \\
\hline & After & 12.03 & 1.11 \\
\hline \multirow{2}{*}{ White Blood Cells ${ }^{\star *}$} & Before & 7468.95 & 3233.23 \\
\hline & After & 5800.00 & 1123.94 \\
\hline \multirow{2}{*}{ Neutrophils ${ }^{\star}$} & Before & 5853.16 & 2598.15 \\
\hline & After & 5868.95 & 2021.10 \\
\hline \multirow{2}{*}{ Platelet Count* } & Before & $189,763.16$ & $81,980.69$ \\
\hline & After & $184,784.21$ & $42,868.08$ \\
\hline \multirow{2}{*}{ SGOT $^{* *}$} & Before & 34.66 & 22.47 \\
\hline & After & 24.74 & 20.52 \\
\hline
\end{tabular}


Continued

\begin{tabular}{|c|c|c|c|}
\hline \multirow{2}{*}{$\mathrm{SGPT}^{* *}$} & Before & 37.03 & 25.70 \\
\hline & After & 26.05 & 17.96 \\
\hline \multirow{2}{*}{ Serum Creatinine $e^{\star *}$} & Before & 0.97 & 0.36 \\
\hline & After & 0.74 & 0.16 \\
\hline \multirow{2}{*}{ Blood Urea Nitrogen ${ }^{\star}$} & Before & 15.57 & 10.04 \\
\hline & After & 12.44 & 9.65 \\
\hline \multirow{2}{*}{ Prothrombin Time ${ }^{\star}$} & Before & 1.22 & 0.43 \\
\hline & After & 1.11 & 0.03 \\
\hline \multirow{2}{*}{ Sodium ${ }^{*}$} & Before & 134.63 & 5.86 \\
\hline & After & 134.89 & 3.78 \\
\hline \multirow{2}{*}{ Potassium $^{\star *}$} & Before & 4.18 & 0.44 \\
\hline & After & 3.77 & 0.35 \\
\hline \multirow{2}{*}{ Chloride* } & Before & 99.50 & 3.61 \\
\hline & After & 98.79 & 3.21 \\
\hline
\end{tabular}

${ }^{\star}$ Pre and post treatment values are same $(\mathrm{p}>0.05) ;{ }^{*}$ Pre-treatment value is higher $(\mathrm{p}<$ $0.05) ;{ }^{* *}$ Post-treatment value is higher $(\mathrm{p}<0.05)$.

function) or remained same (neutrophils, platelets, blood urea nitrogen, electrolytes).

Importantly, haemoglobin level showed a sharp increase after the nutritional intervention over the study period. No major statistical difference $(p>0.05)$ was observed in neutrophil and platelet count over the study period. Prothrombin time (PT/INR), sodium and chloride levels also remained unaltered ( $\mathrm{p}>0.05)$. A steady decrease was observed in SGPT and SGOT level which is indicative of liver function improvement $(\mathrm{p}<0.05)$. Statistically significant difference in serum creatinine and blood urea nitrogen values over the period of study were indicative of renal function improvement $(\mathrm{p}<0.05)$. While a statistically significant $(p<0.05)$ decrease was observed in WBC, neutrophil values remained same over the period of study indicating that patients in general developed lesser infections during chemotherapy. The biochemical data strongly indicates that EON therapy helped in improvement of most of biochemical parameters of patients and prevented deterioration of others (Figure 2).

\subsection{Impact of Eon Therapy on Quality of life}

ECOG (Table 6) and MST scales were used to evaluate physical/mental and nutritional status of each patient and the outcome of the evaluation was used for assessment of QoL of patients before and at the end of study duration. Figure 3 depicts the outcome of ECOG and MST evaluation before and at the end of study.

Around $55 \%$ of volunteers had some physical concerns with respect to daily activities at the start of the study and the percentage of these volunteers dropped 


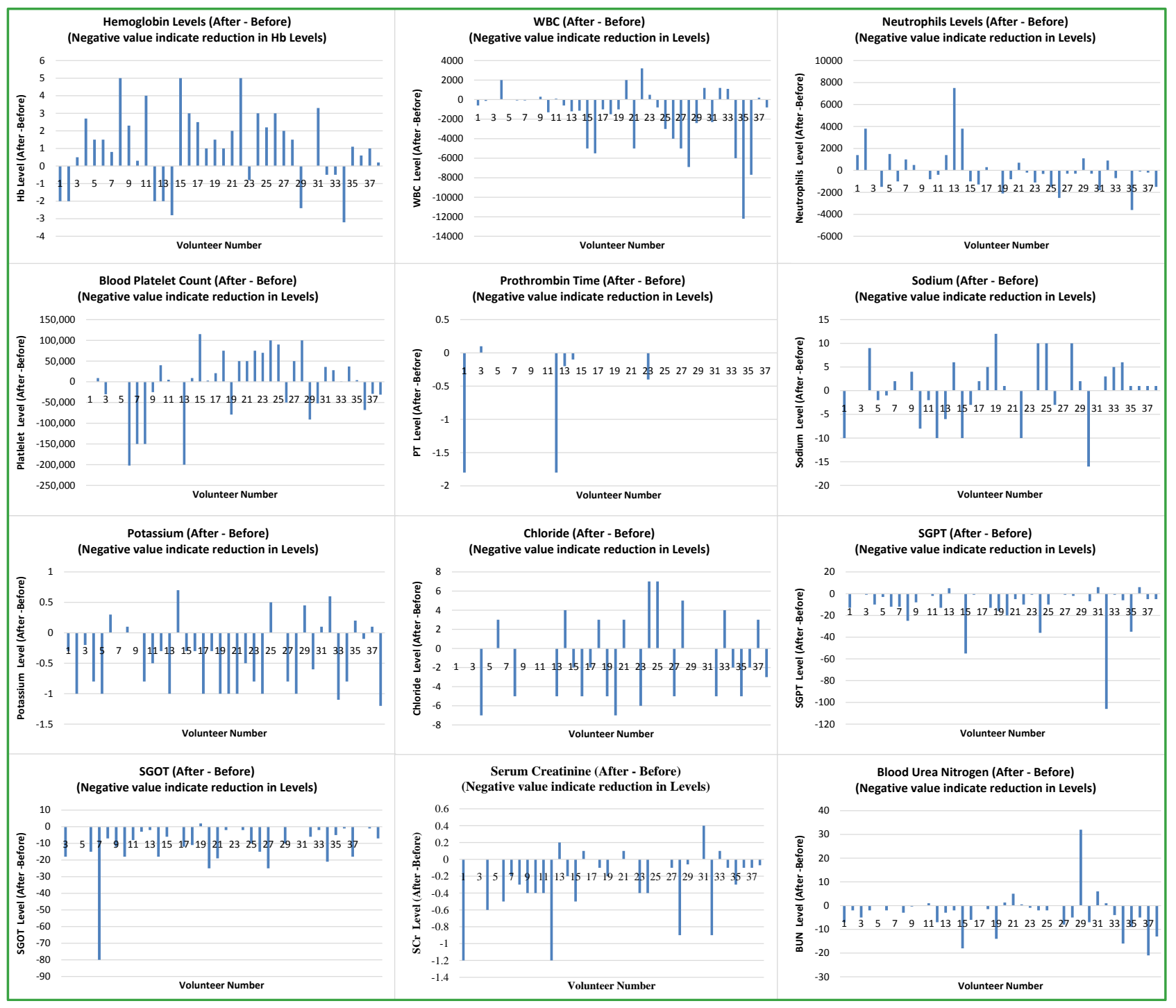

Figure 2. Changes in biochemical parameters of individual volunteers over the study period.

Table 6. ECOG performance scale.

\begin{tabular}{cl}
\hline Grade & \multicolumn{1}{c}{ ECOG Performance Status } \\
\hline 0 & Fully active, able to carry on all pre-disease performance without restriction \\
1 & $\begin{array}{l}\text { Restricted in physically strenuous activity but ambulatory and able to carry } \\
\text { out work of a light or sedentary nature, e.g., light housework, office work }\end{array}$ \\
2 & $\begin{array}{l}\text { Ambulatory and capable of all selfcare but unable to carry out any work } \\
\text { activities; up and about more than } 50 \% \text { of waking hours }\end{array}$ \\
3 & $\begin{array}{l}\text { Capable of only limited selfcare; confined to bed or chair more than } 50 \% \text { of } \\
\text { waking hours }\end{array}$ \\
4 & $\begin{array}{l}\text { Completely disabled; cannot carry on any selfcare; totally confined to bed or } \\
\text { chair }\end{array}$ \\
5 & Dead
\end{tabular}




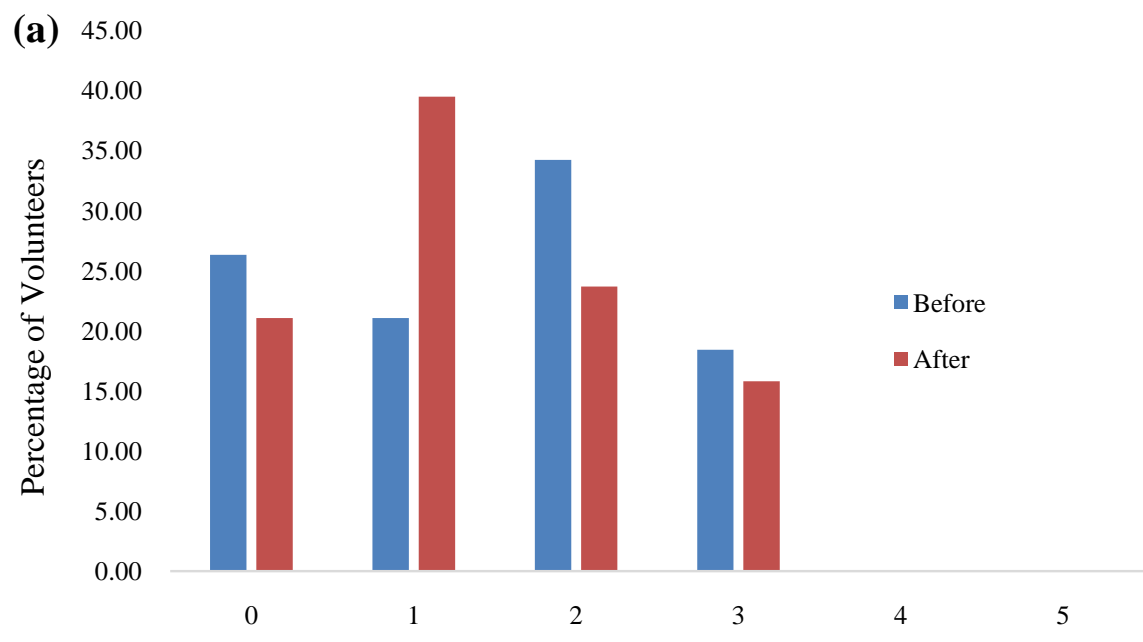

ECOG Rating on Scale of 1 to 5

(b)

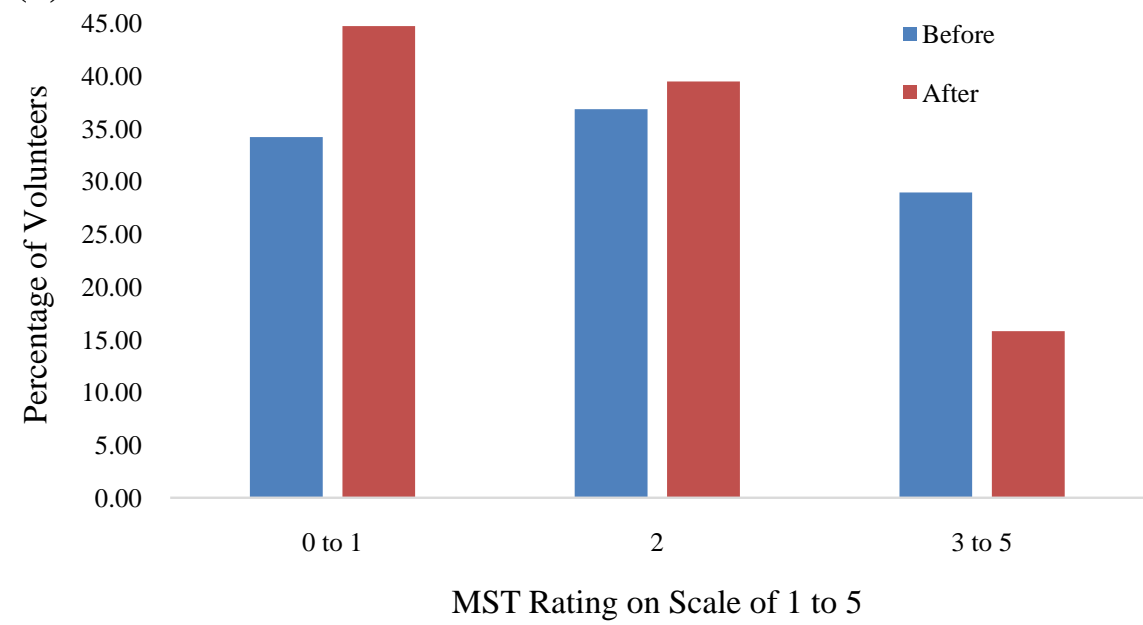

Figure 3. QoL Data: Change in percentage of volunteers with restricted physical activity and risk of developing malnutrition during the study (a) ECOG Scale (b) MST Scale.

to around $40 \%$ even after going through chemotherapy cycles. Almost similar results were obtained using MST scale. At the start of study, the percentage of volunteer with no risk, moderate risk and high risk of malnutrition were $35 \%$, $35 \%$ and $30 \%$ respectively. After the study duration the percentage of volunteer with no risk, moderate risk and high risk of malnutrition was $45 \%, 45 \%$ and $15 \%$ respectively (Figure 3).

Based upon outcome of both these scales along with no reports of adverse event specific to nutritional supplements, it can easily be concluded that patients had a better QoL. This observation is further substantiated by anti-cachexia effect and improvement in most of the biochemical parameters.

\section{Discussion}

Cachexia, particularly in cancer, is an insidious, complex and multifactorial syndrome, pathophysiology of which is characterized by a negative protein and ener- 
gy balance driven by a varying combination of reduced food intake (primary anorexia) and altered metabolism (hypercatabolism and hypoanabolism). A salient diagnostic feature of cancer cachexia (excluding precachexia) is, therefore, involuntary weight loss, rendering screening for weight loss along with temporal monitoring of body weight during prognosis an important clinical assessment [8] [12]. It turns out that cachexia is partially reversible in both of its components-diminished food intake as well as aberrant metabolism-and can be treated by nutritional intervention [17] [18] [19]. Few reports revealed skeletal muscle depletion, depicted by image analyses (CT, MRI, etc), in patients who otherwise would not be doubted for any reduction in body mass [20] [21]. Patients, with such deviant body composition, have shown high susceptibility towards therapeutic toxicity which could be attributed to enhanced drug exposure in muscle-depleted individuals [22] [23].

Local inflammation, described as one of the hallmarks of cancer, provides a microenvironment which reinforces malignant growth [24] [25] [26]. It turns out that the energy homeostasis is perturbed in chronic inflammatory states owing to the excess fuel consumption of an activated immune system which, impacting negatively, results in a metabolic shift towards catabolism with a subsequent resistance for anabolism, promoting malnutrition and inducing cachexia and fatigue [27] [28]. One propounded mechanism of cancer cachexia is, thus, an inflammation-driven congregated physiological response of substrate mobilization, an adaptive response towards accessing protein and energy stored in body [29] [30]. It is evident that pro-inflammatory cytokine activity gets elevated during progression of the disease marked by the generation of acute-phase response (APR) proteins, viz, C-reactive protein (CRP) and fibrinogen. Cytokines, including tumor necrosis factor-alpha (TNF- $\alpha$ ), interleukin-1 (IL-1), IL-6, and interferon-gamma (IFN- $\gamma$ ) have shown to play roles in cancer cachexia [31]. Moreover, studies demonstrated that cancer patients having a single nucleotide polymorphism with downregulated expression of $\mathrm{P}$ selectin glycoprotein ligand-1 are less prone to develop cachexia compared to other common genotypic counterparts [32]. Using a C57BL/6 murine model, Das et al. reported that genetic removal of adipose triglyceride lipase improves cachexia pathology [33].

The aim of cachexia therapy is, indubitably, to impede these responses to inflammation reinstating positive energy balance and to stimulate the gain of skeletal muscle mass. To this end, it is important to understand the specific management of the inflammatory pathways which initiate and propagate the process. Significant scientific efforts have been directed towards deciphering the role of various pharmacological entities to resist the disease, such as, medroxyprogesterone, megestrol acetate, ghrelin, cannabinoids, melanocortin antagonists, thalidomide, etanercept, omega-3 fatty acids (eicosapentaenoic acid), herbal medicine (kampo), corticosteroids, non-steroidal anti-inflammatory drugs, $\beta 2$-adrenergic agonists, erythropoietin, etc. [31]. On the other hand, screening for malnutrition, assessing the nutritional and metabolic status, individualized multimodal care, evaluate and adapt care, counselling, enriching food, oral nutritional sup- 
plements, enteral tube feeding and parenteral nutrition, etc. have also become a part of the existing modalities [34]. Recommended protein intake to circumvent anabolic resistance in patients with cancer cachexia is $1.0-2.0 \mathrm{~g} / \mathrm{Kg}$ per day, food energy intake being increased by $300-400 \mathrm{Kcal}$ per day [7] [34]. The best way to look into the future is to combine these two to beget a new level of nutritional and metabolic patient care where commonality in definitions and grading systems will be established towards efficient treatment with nutritional intervention along with adequate medical resources.

To accomplish the task, EON's proprietary products named as EON Therapy are positioned during different stages and cycles of cancer medication. Much to our intrigue, they are showing very promising results in terms of improving quality of life and body weight gain in all the patients enrolled for the treatment. This can be attributed to the ingredients we are using in our formula. It turns out that plant polyphenols have become a part of the zeitgeist due to their ability to sensitize drug-resistant cancer cells towards chemotherapeutics as well as protect non-target tissues from damage due to their antioxidant and anti-inflammatory properties. The most popular among these polyphenols is, indubitably, curcumin - which is extracted from the rhizomes of Curcuma longa (known as turmeric) and has a multitude of therapeutic effects in various cancers [35]. It turns out that $\beta$-carotene, a polyene dietary carotenoids acts as an immune modulator with a potential to quench singlet oxygen, scavenge free radicals (ROS) at lower partial oxygen pressures, provide photoprotection to photosynthetic organisms and prevent cancer, heart diseases, and age-related macular degeneration [36]. The anti-inflammatory activity it exerts can be attributed to the upregulation of Heme oxygenase 1 (Hmox1) mRNA expression. Using lipopolysaccharide (LPS) stimulated RAW 264.7 macrophages, anti-inflammatory property of the branched chain amino acids (BCAAs) was evaluated where BCAA diminished NO production, down regulated iNOS, COX-2, IL-6 mRNA expression [37]. Many proteins involved in DNA damage, signalling and repair, replicative enzymes and transcription factors, need Zinc ( $\mathrm{Zn}$ ), a first transition Group IIB element and an essential mineral, for proper functioning. Zinc deficiency has also been shown to impair the DNA binding abilities of p53, nuclear factor $\kappa \mathrm{B}(\mathrm{NF} \kappa \mathrm{B})$, and $\mathrm{AP}-1$ transcription factors in rat glioma $\mathrm{C} 6$ cells. Few in vivo studies showed an effect of $\mathrm{Zn}$ in altering antioxidant status in colonic histoarchitecture of rats [38]. Importantly, a wide range of functions are carried out by probiotics, live beneficial organisms, including direct interactions with the gut luminal microbiota, metabolic outcomes, effects on barrier function, and crosstalk with the central nervous system and enteric immunity. They also have shown their potential in the management of Gastroesophageal reflux disease (GERD), an upper digestive tract disorder, often associated with occurrence of cancer [39]. Mechanistically, nutraceuticals mentioned above have exerted their anti-inflammatory properties against cachexia causing local inflammation counter-balancing the negative protein and energy metabolism. Concurrent with the mainstream therapy, copious food intake in the form of nutritional supplemen- 
tation has properly managed cachexia causing reduced food intake. Thus, in both the arms, cancer cachexia is well addressed with EON's nutritional intervention.

This PAN-India PMS validation has prompted us to develop cancer specific nutritional supplementation to be given during prognosis. Strategies are being formulated to conduct more in-depth clinical trials, to investigate the effect of various EON-formulations on multi-drug resistance and recurrence of cancer.

\section{Conclusion and Future Perspective}

These results indicate that EON Therapy played significant role in mitigating malnutrition by arresting weight loss due to cancer induced cachexia. Improvement in biochemical and QoL parameters further substantiate role of EON therapy in general wellness of patients. The results obtained are being substantiated by undertaking a study on larger patient pool in different geographies. This study highlights that research needs to be undertaken for developing nutritional supplements specifically for cancer patients on curative care for better management and prognosis.

\section{Acknowledgements}

We acknowledge authorities of all the hospital sites for providing us with the volunteers required for the PMS study.

\section{Conflicts of Interest}

The authors report there are no competing interests to declare.

\section{References}

[1] Porporato, P.E. (2016) Understanding Cachexia as a Cancer Metabolism Syndrome. Oncogenesis, 5, Article No. e200. https://doi.org/10.1038/oncsis.2016.3

[2] Marceca, G.P., Londhe, P. and Calore, F. (2020) Management of Cancer Cachexia: Attempting to Develop New Pharmacological Agents for New Effective Therapeutic Options. Frontiers in Oncology, 10, Article No. 298. https://doi.org/10.3389/fonc.2020.00298

[3] Hébuterne, X., Lemarié, E., Michallet, M., de Montreuil, C.B., Schneider, S.M. and Goldwasser, F. (2014) Prevalence of Malnutrition and Current Use of Nutrition Support in Patients with Cancer. Journal of Parenteral and Enteral Nutrition, 38, 196-204. https://doi.org/10.1177/0148607113502674

[4] Bruggeman, A.R., Kamal, A.H., LeBlanc, T.W., Ma, J.D., Baracos, V.E. and Roeland, E.J. (2016) Cancer Cachexia: Beyond Weight Loss. Journal of Oncology Practice, 12, 1163-1171. https://doi.org/10.1200/JOP.2016.016832

[5] Arends, J., Baracos, V., Bertz, H., Bozzetti, F., Calder, P.C., Deutz, N.E.P., Erickson, N., et al. (2017) ESPEN Expert Group Recommendations for Action against Cancer-Related Malnutrition. Clinical Nutrition, 36, 1187-1196. https://doi.org/10.1016/j.clnu.2017.06.017

[6] Lu, Z., Yang, L., Yu, J., Lu, M., Zhang, X., Li, J., Zhou, J., Wang, X., Gong, J., Gao, J., Li, J., Li, Y. and Shen, L. (2014) Change of Body Weight and Macrophage Inhibitory 
Cytokine-1 during Chemotherapy in Advanced Gastric Cancer: What Is Their Clinical Significance? PLOS ONE, 9, Article ID: e88553. https://doi.org/10.1371/journal.pone.0088553

[7] Arends, J., Bachmann, P., Baracos, V., Barthelemy, N., Bertz, H., Bozzetti, F., Fearon, K., Hütterer, E., Isenring, E., Kaasa, S., Krznaric, Z., Laird, B., Larsson, M., Laviano, A., Mühlebach, S., Muscaritoli, M., Oldervoll, L., Ravasco, P., Solheim, T., Strasser, F., de van der Schueren, M. and Preiser, J.C. (2017) ESPEN Guidelines on nutrition in cancer patients. Clinical Nutrition, 36, 11-48.

https://doi.org/10.1016/j.clnu.2016.07.015

[8] Fearon, K., Arends, J. and Baracos, V. (2013) Understanding the Mechanisms and Treatment Options in Cancer Cachexia. Nature Review Clinical Oncology, 10, 90-99. https://doi.org/10.1038/nrclinonc.2012.209

[9] Aapro, M., Arends, J., Bozzetti, F., Fearon, K., Grunberg, S.M., Herrstedt, J., Hopkinson, J., Jacquelin-Ravel, N., Jatoi, A., Kaasa, S. and Strasser F. (2014) Early Recognition of Malnutrition and Cachexia in the Cancer Patient: A Position Paper of a European School of Oncology Task Force. Annals of Oncology, 25, 1492-1499. https://doi.org/10.1093/annonc/mdu085

[10] Bozzetti, F., Arends, J., Lundholm, K., Micklewright, A., Zurcher, G. and Muscaritoli, M. (2009) ESPEN Guidelines on Parenteral Nutrition: Non-Surgical Oncology. Clinical Nutrition, 28, 445-454. https://doi.org/10.1016/j.clnu.2009.04.011

[11] Cotogni, P., Pedrazzoli, P., De Waele, E., Aprile, G., Farina, G., Stragliotto, S., De Lorenzo, F. and Caccialanza, R. (2019) Nutritional Therapy in Cancer Patients Receiving Chemoradiotherapy: Should We Need Stronger Recommendations to Act for Improving Outcomes? Journal of Cancer, 10, 4318-4325. https://doi.org/10.7150/jca.31611

[12] Cotogni, P. (2016) Enteral versus Parenteral Nutrition in Cancer Patients: Evidences and Controversies. Annals of Palliative Medicine, 5, 42-49.

[13] August, D.A. and Huhmann, M.B. (2009) ASPEN Clinical Guidelines: Nutrition Support Therapy during Adult Anticancer Treatment and in Hematopoietic Cell Transplantation. Journal of Parenteral and Enteral Nutrition, 33, 472-500. https://doi.org/10.1177/0148607109341804

[14] Yalcin, S., Gumus, M., Oksuzoglu, B., Ozdemir, F., Evrensel, T., Sarioglu, A.A., Sahin, B., Mandel, N.M. and Goker, E. (2019) Nutritional Aspect of Cancer Care in Medical Oncology Patients. Clinical Therapy, 41, 2382-2396.

https://doi.org/10.1016/j.clinthera.2019.09.006

[15] Azam, F., Latif, M.F., Farooq, A., Tirmazy, S.H., AlShahrani, S., Bashir, S. and Bukhari, N. (2019) Performance Status Assessment by Using ECOG (Eastern Cooperative Oncology Group) Score for Cancer Patients by Oncology Healthcare Professionals. Case Reports in Oncology, 12, 728-736. https://doi.org/10.1159/000503095

[16] Di Bella, A., Croisier, E., Blake, C., Pelecanos, A., Bauer, J. and Brown, T. (2020) Assessing the Concurrent Validity and Interrater Reliability of Patient-Led Screening Using the Malnutrition Screening Tool in the Ambulatory Cancer Care Outpatient Setting. Journal of the Academy of Nutrition and Dietetics, 120, 1210-1215. https://doi.org/10.1016/j.jand.2019.10.015

[17] Kubrak, C., Olson, K., Jha, N., Jensen, L., McCargar, L., Seikaly, H., Harris, J., Scrimger, R., Parliament, M. and Baracos, V.E. (2010) Nutrition Impact Symptoms: Key Determinants of Reduced Dietary Intake, Weight Loss, and Reduced Functional Capacity of Patients with Head and Neck Cancer before Treatment. Head Neck, 32, 290-300. https://doi.org/10.1002/hed.21174 
[18] Batista, G.A., Souza, A.L., Marin, D.M., Sider, M., Melhado, V.C., Fernandes, A.M. and Alegre, S.M. (2017) Body Composition, Resting Energy Expenditure and Inflammatory Markers: Impact in Users of Depot Medroxyprogesterone Acetate after 12 Months Follow-Up. Archives of Endocrinology and Metabolism, 61, 70-75. https://doi.org/10.1590/2359-3997000000202

[19] Akbulut, G. (2011) New Perspective for Nutritional Support of Cancer Patients: Enteral/Parenteral Nutrition. Experimental and Therapeutic Medicine, 2, 675-684. https://doi.org/10.3892/etm.2011.247

[20] Tan, B.H., Birdsell, L.A., Martin, L., Baracos, V.E. and Fearon K.C. (2009) Sarcopenia in An Overweight or Obese Patient Is an Adverse Prognostic Factor in Pancreatic Cancer. Clinical Cancer Research, 15, 6973-6979. https://doi.org/10.1158/1078-0432.CCR-09-1525

[21] Prado, C.M., Lieffers, J.R., McCargar, L.J., Reiman, T., Sawyer, M.B., Martin, L. and Baracos V.E. (2008) Prevalence and Clinical Implications of Sarcopenic Obesity in Patients with Solid Tumours of the Respiratory and Gastrointestinal Tracts: A Population-Based Study. The Lancet Oncology, 9, 629-635. https://doi.org/10.1016/S1470-2045(08)70153-0

[22] Prado, C.M., Antoun, S., Sawyer, M.B. and Baracos, V.E. (2011) Two Faces of Drug Therapy in Cancer: Drug-Related Lean Tissue Loss and Its Adverse Consequences to Survival and Toxicity. Current Opinion in Nutrition and Metabolic Care, 14, 250-254. https://doi.org/10.1097/MCO.0b013e3283455d45

[23] Mir, O., Coriat, R., Blanchet, B., Durand, J.P., Boudou-Rouquette, P., Michels, J., Ropert, S., Vidal, M., Pol, S., Chaussade, S. and Goldwasser, F. (2012) Sarcopenia Predicts Early Dose-Limiting Toxicities and Pharmacokinetics of Sorafenib in $\mathrm{Pa}$ tients with Hepatocellular Carcinoma. PLoS ONE, 7, Article ID: e37563. https://doi.org/10.1371/journal.pone.0037563

[24] Zhao, H., Wu, L., Yan, G., Chen, Y., Zhou, M., Wu, Y. and Li, Y. (2021) Inflammation and Tumor Progression: Signaling Pathways and Targeted Intervention. Signal Transduction and Targeted Therapy, 6, Article No. 263.

https://doi.org/10.1038/s41392-021-00658-5

[25] Greten, F.R. and Grivennikov, S.I. (2019) Inflammation and Cancer: Triggers, Mechanisms, and Consequences. Immunity, 51, 27-41.

https://doi.org/10.1016/j.immuni.2019.06.025

[26] Hanahan, D. and Weinberg R.A. (2011) Hallmarks of Cancer: The Next Generation. Cell, 144, 646-674. https://doi.org/10.1016/j.cell.2011.02.013

[27] Straub, R.H. (2012) Evolutionary Medicine and Chronic Inflammatory State-Known and New Concepts in Pathophysiology. Journal of Molecular Medicine, 90, 523-534. https://doi.org/10.1007/s00109-012-0861-8

[28] Winter, A., MacAdams, J. and Chevalier, S. (2012) Normal Protein Anabolic Response to Hyperaminoacidemia in Insulin-Resistant Patients with Lung Cancer Cachexia. Clinical Nutrition, 31, 765-773. https://doi.org/10.1016/j.clnu.2012.05.003

[29] Straub, R.H., Cutolo, M., Buttgereit, F. and Pongratz G. (2010) Energy Regulation and Neuroendocrine-Immune Control in Chronic Inflammatory Diseases. Journal of Internal Medicine, 267, 543-560. https://doi.org/10.1111/j.1365-2796.2010.02218.x

[30] Honors, M.A. and Kinzig, K.P. (2012) The Role of Insulin Resistance in the Development of Muscle Wasting during Cancer Cachexia. Journal of Cachexia, Sarcopenia and Muscle, 3, 5-11. https://doi.org/10.1007/s13539-011-0051-5

[31] Aoyagi, T., Terracina, K.P., Raza, A., Matsubara, H. and Takabe, K. (2015) Cancer 
Cachexia, Mechanism and Treatment. World J Gastrointestinal Oncology, 7, 17-29. https://doi.org/10.4251/wjgo.v7.i4.17

[32] Tan, B.H., Fladvad, T., Braun, T.P., Vigano, A., Strasser, F., Deans, D.A., Skipworth, R.J., Solheim, T.S., Damaraju, S., Ross, J.A., Kaasa, S., Marks, D.L., Baracos, V.E., Skorpen, F. and Fearon, K.C. (2012) P-Selectin Genotype Is Associated with the Development of Cancer Cachexia. EMBO Molecular Medicine, 4, 462-471.

https://doi.org/10.1002/emmm.201200231

[33] Das, S.K., Eder, S., Schauer, S., Diwoky, C., Temmel, H., Guertl, B., Gorkiewicz, G., Tamilarasan, K.P., Kumari, P., Trauner, M., Zimmermann, R., Vesely, P., Haemmerle, G., Zechner, R. and Hoefler G. (2011) Adipose Triglyceride Lipase Contributes to Cancer-Associated Cachexia. Science, 333, 233-238. https://doi.org/10.1126/science.1198973

[34] Arends, J. (2018) Struggling with Nutrition in Patients with Advanced Cancer: Nutrition and Nourishment-Focusing on Metabolism and Supportive care. Annals of Oncology, 29, ii27-ii34. https://doi.org/10.1093/annonc/mdy093

[35] Giordano, A. and Tommonaro, G. (2019) Curcumin and Cancer. Nutrients, 11, Article No. 2376. https://doi.org/10.3390/nu11102376

[36] Kawata, A., Murakami, Y., Suzuki, S. and Fujisawa, S. (2018) Anti-Inflammatory Activity of $\beta$-Carotene, Lycopene and Tri- $n$-Butylborane, a Scavenger of Reactive Oxygen Species. In Vivo, 32, 255-264. https://doi.org/10.21873/invivo.11232

[37] Lee, J.H., Park, E., Jin, H.J., Lee, Y., Choi, S.J., Lee, G.W., Chang, P.S. and Paik, H.D. (2017) Anti-Inflammatory and Anti-Genotoxic Activity of Branched Chain Amino Acids (BCAA) in Lipopolysaccharide (LPS) Stimulated RAW 264.7 Macrophages. Food Science and Biotechnology, 26, 1371-1377. https://doi.org/10.1007/s10068-017-0165-4

[38] Costello, L.C. and Franklin, R.B. (2012) Cytotoxic/Tumor Suppressor Role of Zinc for the Treatment of Cancer: An Enigma and an Opportunity. Expert Review of Anticancer Therapy, 12, 121-128. https://doi.org/10.1586/era.11.190

[39] Cheng, J. and Ouwehand, A.C. (2020) Gastroesophageal Reflux Disease and Probiotics: A Systematic Review. Nutrients, 12, Article No. 132.

https://doi.org/10.3390/nu12010132 